\title{
Hemodynamic Disturbances in Cerebral Ischemia: Correlation Between Positron Emission Tomographic and Angiographic Findings
}

\author{
Hiroshi TEnjIn, Satoshi UEda, Norihiko MizUKaWA, Yoshio IMAHORI, \\ Akihiko HINO, Yoshio OHMORI and Hisamitsu NAKAHASHI* \\ Department of Neurosurgery, Kyoto Prefectural University of Medicine, Kyoto; \\ *Department of Radiology and Cyclotron Unit, Nishijin Hospital, Kyoto
}

\begin{abstract}
Proper treatment of ischemic stroke requires better understanding of cerebral hemodynamic changes. The hemodynamic changes associated with ischemia were measured using positron emission tomography and related to angiographic findings in the subacute and chronic stages of 17 ischemia patients who showed symptoms of main trunk stenosis of the internal carotid artery system. The hemodynamic factors, cerebral blood flow, cerebral blood volume, cerebral metabolic rate for oxygen, oxygen extraction fraction, and flow/volume ratio, were measured in regions of interest determined from the angiographic stenosis (over 50\%) and compared in each stage. The cerebral blood flow and flow/volume ratio in the territory downstream of the main trunk stenosis and cerebral metabolic rate for oxygen in the whole cortex were decreased in the subacute stage. In the chronic stage, cerebral blood flow and flow/volume ratio decreased mainly in borderzone areas.
\end{abstract}

Key words: positron emission tomography, cerebral ischemia, angiography

\section{Introduction}

A clear understanding of cerebral hemodynamics is important for the proper treatment of ischemic stroke. Recently, positron emission tomography (PET) has allowed the measurement of regional cerebral blood flow (rCBF) and metabolism. In addition, PET images are easily compared with computed tomographic (CT) images making it one of the best methods available for measuring hemodynamics in ischemic stroke. Most published reports ${ }^{2,30)}$ have concentrated on the acute stage and severe ischemic regions where cerebral infarction usually occurs.

Reconstructive vascular surgery is usually performed in the chronic stage, when indicated by symptoms and angiographic findings. ${ }^{22,35)}$ Therefore, the relationship between angiographic findings and cerebral hemodynamics is important, especially in low-perfusion areas. However, the relationship between angiographic findings and hemodynamics in chronicstage patients has received little attention.

Received May 7, 1992; Accepted September 17, 1992
Here, we report our study of hemodynamic changes in subacute and chronic ischemic stroke and discuss the relationship between main trunk stenosis of the cerebral arteries and hemodynamics.

\section{Clinical Materials and Methods}

This study included 17 patients with ischemic symptoms of main trunk stenosis of the internal carotid artery (ICA) system admitted to Kyoto Prefectural University of Medicine or affiliated hospitals from 1988 to 1990 (Table 1). Fifteen were males and two were females, aged between 31 and 79 years. Thirteen normal volunteers aged from 22 to 83 years were also investigated for comparison purposes.

This study investigated patients who showed ischemic symptoms due to low perfusion of the ICA systems. ${ }^{19)}$ Patients showing symptoms of vertebrobasilar system or diffuse brain damage, consciousness disturbance, ${ }^{12)}$ thrombus in the heart by echocardiography, apparent embolic infarctions, for example with rapid onsets within a few minutes, and severe cardiopulmonary disease, diabetes mellitus, and kidney disease complications were excluded. 
Table 1 Summary of patients

\begin{tabular}{|c|c|c|c|c|c|c|}
\hline Case No. & Age & Sex & Diagnosis & $\begin{array}{c}\text { PET study } \\
\text { (days after onset) }\end{array}$ & $\begin{array}{l}\text { Angiographic } \\
\text { findings }\end{array}$ & $\begin{array}{l}\text { Collateral } \\
\text { circulation }\end{array}$ \\
\hline 1 & 55 & M & stroke & 11 & $\begin{array}{l}\text { lt ICA occlusion, } \\
\text { rt ICA stenosis }(95 \%)\end{array}$ & $\begin{array}{l}\text { good (lt), } \\
\text { good (rt) }\end{array}$ \\
\hline 2 & 61 & $\mathbf{M}$ & stroke & 24 & $\begin{array}{l}\text { It MCA occlusion, } \\
\text { rt ICA occlusion }\end{array}$ & $\begin{array}{l}\text { good (lt), } \\
\text { good (rt) }\end{array}$ \\
\hline 3 & 79 & M & RIND & 21 & rt ICA stenosis $(50 \%)$ & good \\
\hline $4^{*}$ & 31 & M & RIND & $\begin{array}{l}26 \\
99\end{array}$ & $\begin{array}{l}\text { rt ICA occlusion } \\
\text { rt ICA stenosis }(90 \%)\end{array}$ & $\begin{array}{l}\text { good } \\
\text { good }\end{array}$ \\
\hline 5 & 72 & $\mathbf{M}$ & RIND & 20 & rt ICA stenosis $(50 \%)$ & good \\
\hline 6 & 61 & $\mathbf{F}$ & stroke & 28 & rt MCA occlusion & good \\
\hline $7^{*}$ & 38 & $\mathbf{M}$ & stroke & $\begin{array}{r}14 \\
304\end{array}$ & $\begin{array}{l}\text { It MCA occlusion } \\
\text { It MCA occlusion }\end{array}$ & $\begin{array}{l}\text { good } \\
\text { good }\end{array}$ \\
\hline 8 & 72 & $\mathbf{M}$ & stroke & 8 & rt MCA occlusion & poor \\
\hline 9 & 56 & M & TIA & 22 & It MCA stenosis $(50 \%)$ & good \\
\hline 10 & 61 & $\mathbf{M}$ & TIA & 46 & $\begin{array}{l}\text { It ICA stenosis }(90 \%) \\
\text { It ICA stenosis }(90 \%)\end{array}$ & $\begin{array}{l}\text { poor }(\mathrm{lt}) \\
\text { poor }(\mathrm{rt})\end{array}$ \\
\hline 11 & 68 & $\mathbf{M}$ & TIA & 31 & $\begin{array}{l}\text { lt ICA stenosis }(90 \%) \text {, } \\
\text { rt ICA stenosis }(90 \%)\end{array}$ & $\begin{array}{l}\text { poor (lt), } \\
\text { poor (rt) }\end{array}$ \\
\hline 12 & 48 & $\mathbf{M}$ & stroke & 730 & $\begin{array}{l}\text { lt ICA stenosis }(90 \%) \\
\text { rt ICA stenosis }(90 \%)\end{array}$ & $\begin{array}{l}\text { poor }(\mathrm{lt}) \\
\text { poor }(\mathrm{rt})\end{array}$ \\
\hline 13 & 54 & M & stroke & 180 & It ICA occlusion & good \\
\hline 14 & 69 & $\mathbf{M}$ & stroke & 70 & rt ICA stenosis $(90 \%)$ & poor \\
\hline 15 & 34 & M & RIND & 65 & It MCA stenosis $(99 \%)$ & good \\
\hline 16 & 66 & $\mathrm{~F}$ & RIND & 51 & rt MCA stenosis $(63 \%)$ & poor \\
\hline 17 & 63 & M & stroke & 90 & rt MCA stenosis (50\%) & poor \\
\hline
\end{tabular}

${ }^{*}$ PET studies were repeated in these cases. RIND: reversible ischemic neurological deficits, TIA: transient ischemic attacks.

Blood pressure, hematocrit, and blood gas measurements were made in all patients and those with mean arterial blood pressure (MABP) under $80 \mathrm{mmHg}$ or over $120 \mathrm{mmHg}$, hematocrit under $30 \%$ or over $50 \%,{ }^{11)}$ or $\mathrm{PaCO}_{2}$ under $30 \mathrm{mmHg}$ or over $50 \mathrm{mmHg}$ were also excluded.

Reconstructive surgery was usually performed after 4 weeks of ischemia to prevent surgical complications, i.e. hemorrhagic infarction. ${ }^{6}$ Postcontrast CT scans demonstrate contrast enhancement in infarction areas before 4 weeks. ${ }^{32)}$ Accordingly, this study defined the subacute stage as between 4 and 28 days after ischemic insult, and the chronic stage as later than day 28 . In cases of repeated ischemic insult, the stage was defined by the time since the last insult. Clinical examination showed that three patients had transient ischemic attacks, five had reversible ischemic neurological deficits, and nine had completed stroke. This classification was independent of $\mathrm{CT}$ findings and considered relatively unimportant in this study.

All patients underwent bilateral internal carotid angiography, CT, and PET studies. Patients showing diffuse brain atrophy on CT scans were excluded from this study. Patients with small low-density areas in the white matter, basal ganglia, and cortex were included.

Angiograms in the arterial phase were evaluated as follows. Main trunk stenosis was diagnosed when the stenosis was over $50 \%$ in the ICA, the main stem of middle cerebral artery (MCA), or the main branch of the MCA. 50\% stenosis was chosen because decreased blood flow occurs at over $50 \%$ stenosis of the main trunk. ${ }^{13,34)}$ Occlusion was included in this diagnostic method. The stenosis ratio was derived from the equation: $(\mathrm{A}-\mathrm{B}) / \mathrm{A} \times 100(\%)$, where $\mathrm{A}$ is the primary canal width at the most severe stenosis or normal canal width in the distal portion of the bulb in ICA stenosis cases, and B is the minimum diameter. The primary canal width was determined at the proximal and distal parts of the lesion from the angiograms (Fig. 1). ${ }^{4}$ An angiographic stenosis of $50 \%$ as obtained by this method is almost equivalent to $75 \%$ stenosis obtained as the sectional area. Collateral circulation to the affected area was determined by collateral circulation through the circle of Willis, the ophthalmic artery, or cortical anastomosis. Good collateral circulation was defined 

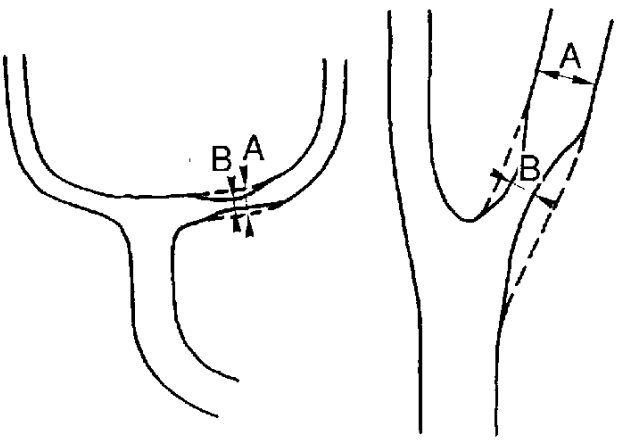

Fig. 1 Evaluation of stenosis. Stenosis ratio was calculated by $(\mathrm{A}-\mathrm{B}) / \mathrm{A} \times 100(\%)$. A: primary canal width at the most severe stenosis or normal canal width in the distal portion of the bulb in patients with ICA stenosis, B: minimum diameter.

as a condition in which at least one vessel of the circle of Willis, the ophthalmic artery, or the cortical vessels provides adequate blood to the ischemic hemisphere.

A total of 19 PET studies were performed, nine in the subacute stage and 10 in the chronic stage. PET was performed using a Headtome 3 PET scanner (Shimadzu Co., Kyoto) with an image resolution of $8.6 \mathrm{~mm}$ at full-width half-maximum and $13.6 \mathrm{~mm}$ thickness. The three tomographic planes were set to be the same as those used for the previous CT scans. The CT and PET scanners were positioned using lead marks attached to each patient. The CT scans were based on the orbitomeatal line. The rCBF, regional oxygen extraction fraction (rOEF), and regional cerebral metabolic rate for oxygen $\left(\mathrm{rCMRO}_{2}\right.$ ) were measured using an oxygen-15-labeled gas steady-state technique. ${ }^{7}$ Regional cerebral blood volume ( $\mathrm{CBBV}$ ) was measured after bolus inhalation of oxygen-15-labeled carbon monoxide gas. ${ }^{231}$ The overestimation of rOEF was corrected using the rCBV values. ${ }^{15)} \mathrm{We}$ also calculated the $\mathrm{rCBF} / \mathrm{rCBV}$ ratio. $\left.{ }^{8}\right)$ Each individual was studied in a dark room without sedation.

Thirty to $40144 \mathrm{~mm}^{2}$ regions of interest (ROIs) on the CBF images were chosen by reference to the CT scans (Fig. 2) ${ }^{27)}$ The borderzone areas were defined between the anterior cerebral artery and the MCA territories, and between the MCA and the posterior cerebral artery territories for MCA stenosis patients, and between the MCA and the posterior cerebral artery territories for ICA stenosis patients. The anterior borderzone is located in the upper midfrontal region and the posterior borderzone in the parieto-occipital and temporo-occipital areas. ${ }^{31)}$ In
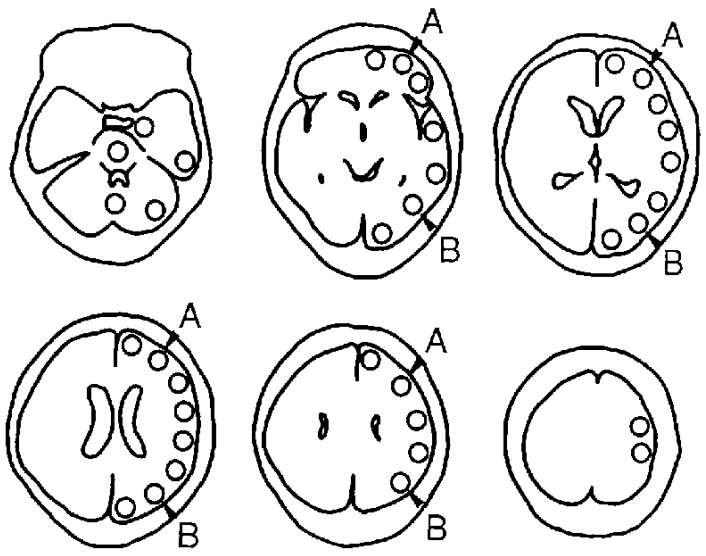

Fig. 2 Diagrammatic representation of each ROI. A, B: borderzone areas in patients with MCA stenosis, B: borderzone areas in patients with ICA stenosis.

our study, only the ROIs in the cortical territory of ICA were used, because the ROIs in the posterior cerebral artery territory were often influenced by radioisotopes in the transverse sinus, and ROIs in the subcortical region were not imaged so accurately by our equipment.

The ROIs were classified into three groups as follows: territory downstream of the main trunk stenosis, territory downstream of the non-trunk stenosis, and borderzone areas in the cortex. The hemodynamic values obtained from these areas were compared with values obtained from 13 normal volunteers. To estimate collateral circulation, the hemodynamic values obtained from areas affected by main trunk stenosis were investigated in detail. The patients were classified into good and poor collateral circulation groups.

Wilcoxon's unpaired two-sample rank test was used for comparison of the hemodynamic values in the above areas of patients and normal volunteers. Significance was confirmed when $\mathrm{p}<0.05$.

Informed consent was obtained from both volunteers and patients. This study was approved by the PET Committee in our institute.

\section{Results}

Table 2 shows the physiological and physical data for the subacute- and chronic-stage patients and normal volunteers. There were no statistically significant differences in age, MABP, $\mathrm{PaCO}_{2}$, and hematocrit. The mean and SD of stenosis ratio for subacute- and chronic-stage patients also showed no statistically significant difference. 
Table 2 Physiological and physical parameters in volunteers and patients

\begin{tabular}{lcccccc}
\hline & $\begin{array}{c}\text { No. of } \\
\text { cases }\end{array}$ & $\begin{array}{c}\text { Age } \\
(\mathrm{yrs})\end{array}$ & $\begin{array}{c}\mathrm{MABP} \\
(\mathrm{mmHg})\end{array}$ & $\begin{array}{c}\mathrm{PaCO}_{2} \\
(\mathrm{mmHg})\end{array}$ & $\begin{array}{c}\text { Hematocrit } \\
(\%)\end{array}$ & $\begin{array}{c}\text { Stenosis ratio } \\
(\%)\end{array}$ \\
\hline Volunteers & 13 & $54 \pm 21$ & $94 \pm 5$ & $41.4 \pm 3.2$ & $41.7 \pm 4.4$ & - \\
Patients & 19 & $55 \pm 15$ & $97 \pm 10$ & $39.6 \pm 4.0$ & $39.7 \pm 4.0$ & - \\
$\quad \begin{array}{l}\text { subacute stage } \\
\quad \text { chronic stage }\end{array}$ & 9 & $56 \pm 16$ & $92 \pm 7$ & $39.2 \pm 3.7$ & $39.1 \pm 3.9$ & $86 \pm 22$ \\
\hline
\end{tabular}

Table 3 Hemodynamic parameters in volunteers and patients

\begin{tabular}{|c|c|c|c|c|c|}
\hline & $\begin{array}{c}\mathrm{rCBF} \\
(\mathrm{ml} / 100 \mathrm{gm} / \mathrm{min})\end{array}$ & $\begin{array}{c}\mathrm{rCMRO}_{2} \\
(\mathrm{ml} / 100 \mathrm{gm} / \mathrm{min})\end{array}$ & $\begin{array}{c}\mathrm{rCBV} \\
(\mathrm{ml} / \mathrm{l} 00 \mathrm{gm})\end{array}$ & rOEF & $\begin{array}{c}\mathrm{rCBF} / \mathrm{rCBV} \\
\text { ratio }\end{array}$ \\
\hline \multicolumn{6}{|l|}{ Volunteers } \\
\hline all cortex & $43 \pm 7$ & $3.3 \pm 0.5$ & $4.5 \pm 0.5$ & $0.40 \pm 0.13$ & $9.7 \pm 1.6$ \\
\hline BA & $42 \pm 5$ & $3.2 \pm 0.5$ & $4.5 \pm 0.9$ & $0.43 \pm 0.08$ & $9.6 \pm 1.7$ \\
\hline \multicolumn{6}{|c|}{ Subacute-stage patients } \\
\hline MTS & $34 \pm 5^{* *}$ & $2.6 \pm 0.5^{* *}$ & $4.2 \pm 0.9$ & $0.46 \pm 0.06$ & $8.2 \pm 1.0^{* *}$ \\
\hline NTS & $40 \pm 6$ & $2.8 \pm 0.5^{*}$ & $4.0 \pm 0.3$ & $0.41 \pm 0.04$ & $10.1 \pm 1.4$ \\
\hline $\mathrm{BA}$ & $34 \pm 4^{* *}$ & $2.6 \pm 0.5^{* *}$ & $4.0 \pm 0.7$ & $0.47 \pm 0.06$ & $8.6 \pm 1.2$ \\
\hline \multicolumn{6}{|c|}{ Chronic-stage patients } \\
\hline MTS & $38 \pm 7$ & $3.0 \pm 0.7$ & $4.3 \pm 0.4$ & $0.45 \pm 0.05$ & $8.9 \pm 1.2$ \\
\hline NTS & $44 \pm 8$ & $3.3 \pm 0.7$ & $4.0 \pm 0.3$ & $0.43 \pm 0.04$ & $11.0 \pm 1.4$ \\
\hline BA & $36 \pm 7^{*}$ & $3.1 \pm 0.8$ & $4.3 \pm 0.6$ & $0.48 \pm 0.07$ & $8.6 \pm 1.3^{*}$ \\
\hline
\end{tabular}

${ }^{*} \mathrm{p}<0.05,{ }^{* *} \mathrm{p}<0.01$. BA: borderzone areas, MTS: territory downstream of the main trunk stenosis, NTS: territory downstream of the non-trunk stenosis.

Table 4 Comparison between hemodynamic parameters in good and poor collateral circulation groups

\begin{tabular}{|c|c|c|c|c|}
\hline $\begin{array}{c}\mathrm{rCBF} \\
(\mathrm{ml} / 100 \mathrm{gm} / \mathrm{min})\end{array}$ & $\begin{array}{c}\mathrm{rCMRO}_{2} \\
(\mathrm{ml} / 100 \mathrm{gm} / \mathrm{min})\end{array}$ & $\begin{array}{c}\mathrm{rCBV} \\
(\mathrm{ml} / 100 \mathrm{gm})\end{array}$ & rOEF & $\underset{\substack{\mathrm{rCBF} / \mathrm{rCBV} \\
\text { ratio }}}{ }$ \\
\hline
\end{tabular}

Subacute-stage patients

good collateral circulation

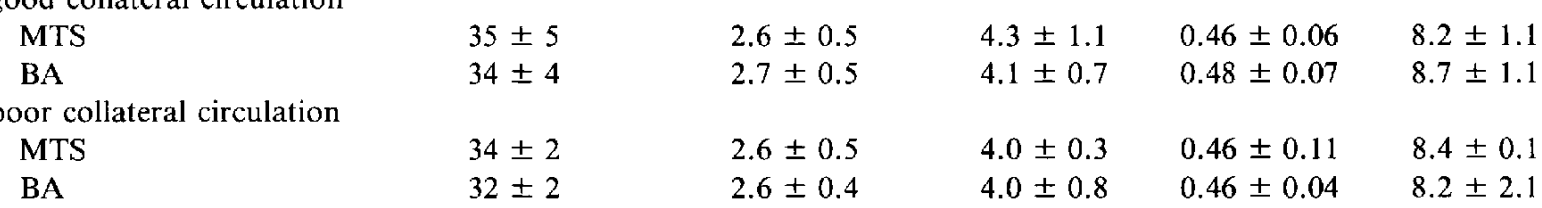

Chronic-stage patients

good collateral circulation

$\begin{array}{llllll}\text { MTS } & 41 \pm 7 & 3.5 \pm 0.4 & 4.5 \pm 0.5 & 0.45 \pm 0.05 & 9.0 \pm 1.4 \\ \text { BA } & 41 \pm 8 & 3.8 \pm 0.5 & 4.6 \pm 0.7 & 0.48 \pm 0.07 & 9.1 \pm 1.7 \\ \text { ooor collateral circulation } & & & & \\ \text { MTS } & 37 \pm 7 & 2.9 \pm 0.7^{*} & 4.3 \pm 0.3 & 0.45 \pm 0.07 & 8.7 \pm 1.2 \\ \text { BA } & 34 \pm 7 & 2.8 \pm 0.7 & 4.3 \pm 0.5 & 0.48 \pm 0.08 & 8.3 \pm 1.1\end{array}$

${ }^{*} \mathrm{p}<0.05$.

Table 3 shows the hemodynamic measurements for the subacute- and chronic-stage patients and normal volunteers. $\mathrm{rCBF}$ and $\mathrm{rCBF} / \mathrm{rCBV}$ ratio decreased in the territory downstream of the main trunk stenosis in the subacute-stage patients. $\mathrm{rCMRO}_{2}$ decreased in all cortical areas in the sub- 

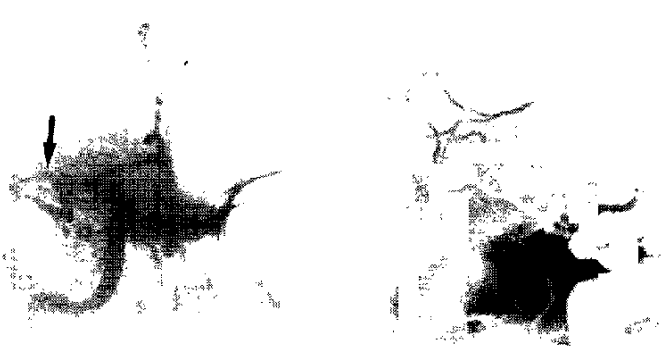

Fig. 3 Case 8. Right carotid angiograms, showing occlusion in the $\mathbf{M}_{1}$ segment (arrow).
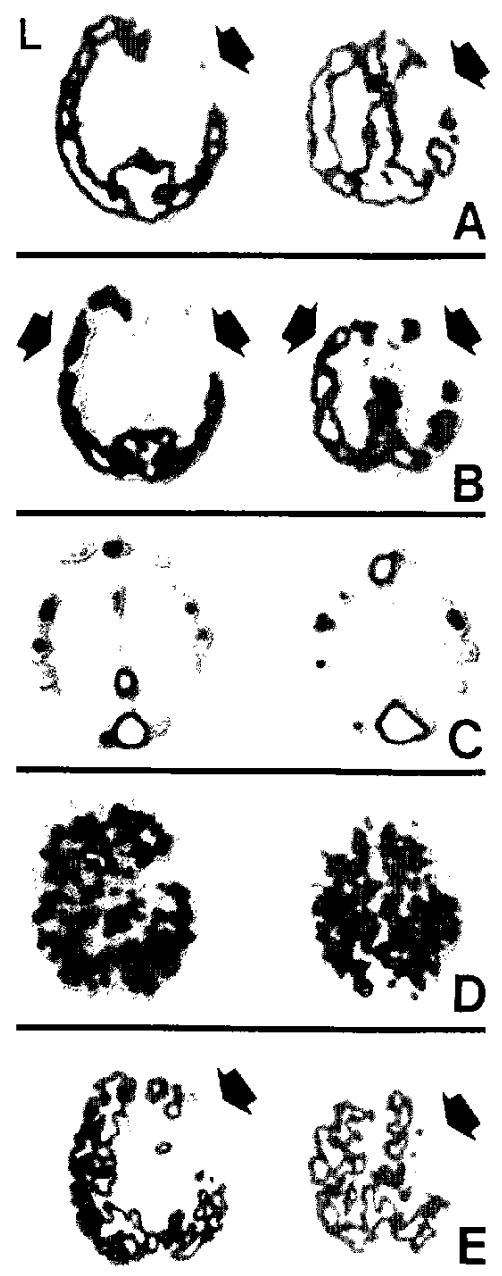

Fig. 4 Case 8. PET images, showing a decrease in $\mathrm{rCBF}$ and $\mathrm{rCBF} / \mathrm{rCBV}$ ratio in the right $\mathrm{MCA}$ territory, and a decrease in $\mathrm{CCMRO}_{2}$ in the bilateral MCA territories (arrows). A: CBF, B: $\mathrm{CMRO}_{2}, \mathrm{C}: \mathrm{CBV}, \mathrm{D}: \mathrm{OEF}, \mathrm{E}: \mathrm{CBF} / \mathrm{CBV}$ ratio.

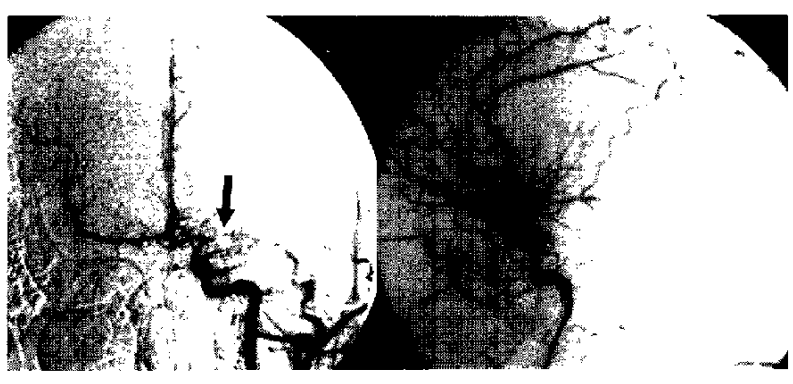

Fig. 5 Case 15. Left carotid angiograms, showing severe stenosis in the left MCA (arrow).
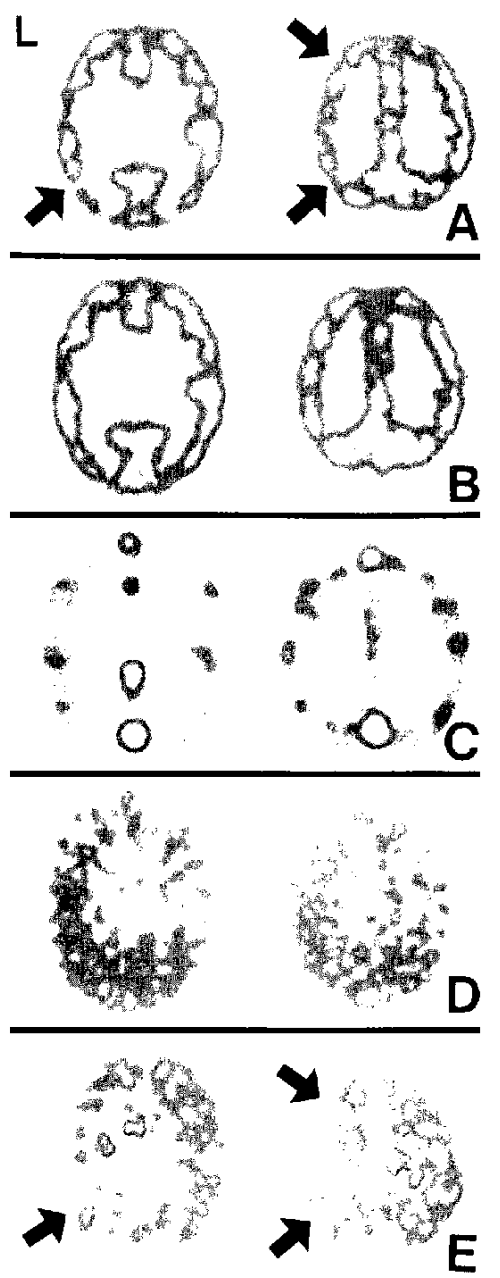

Fig. 6 Case 15. PET images, showing a decrease in $\mathrm{rCBF}$ and $\mathrm{rCBF} / \mathrm{rCBV}$ ratio in the borderzone areas (arrows). A: CBF, B: $\mathrm{CMRO}_{2}, \mathrm{C}$ : $\mathrm{CBV}, \mathrm{D}: \mathrm{OEF}, \mathrm{E}: \mathrm{CBF} / \mathrm{CBV}$ ratio. 
acute stage. In the chronic-stage patients, rCBF and $\mathrm{rCBF} / \mathrm{rCBV}$ ratio decreased mainly in the borderzone areas.

Territory downstream of the main trunk stenosis in poor collateral circulation patients tended to have lower $\mathrm{rCBF}, \mathrm{rCMRO}$, and $\mathrm{rCBF} / \mathrm{rCBV}$ values in the chronic stage, but there were no significant differences between the good and poor collateral circulation groups (Table 4).

\section{Representative Cases}

One subacute- and one chronic-stage patient showing typical correlations between hemodynamic and angiographic findings are described to clarify the statistical data.

Case 8: A 72-year-old male presented with left hemiparesis and dysarthria. Right carotid angiograms showed occlusion in the $M_{1}$ segment (Fig. 3). Eight days postictus, PET evaluation showed decreased $\mathrm{rCBF}(32 \mathrm{ml} / 100 \mathrm{gm} / \mathrm{min})$ and $\mathrm{rCBF} /$ rCBV ratio (8.4) in the right MCA territory and decreased $\mathrm{rCMRO}_{2}(2.4 \mathrm{ml} / 100 \mathrm{gm} / \mathrm{min})$ in the bilateral MCA territories (Fig. 4).

Case 15: A 34-year-old male presented with left hemiparesis and left sensory disturbance. Left carotid angiograms showed severe stenosis in the left MCA (Fig. 5). PET evaluation 65 days after the attack showed decreased rCBF $(32 \mathrm{ml} / 100 \mathrm{gm} / \mathrm{min})$ and $\mathrm{rCBF} / \mathrm{rCBV}$ ratio (8.0) in the borderzone areas (Fig. 6).

\section{Discussion}

There are several possible mechanisms for the hemodynamic disturbances appearing in regions where CT does not show low-density areas. We consider there are three causes for this hemodynamic change. First, the main cause is stenosis of the main trunk of the cerebral artery. In our study, main trunk stenosis and hemodynamic disturbance correlated well. In previous reports, $\mathrm{rCBF}$ and $\mathrm{rCBF} /$ rCBV ratio changes in the territory downstream of the main trunk stenosis or in the borderzone areas also indicated that decreases were caused by main trunk stenosis. ${ }^{24,28,33)}$ Second, the "diaschisis" theory indicates that hemodynamic disturbance is possibly mediated by the neuronal network. ${ }^{14,18,26)}$ This theory explains the contralateral $\mathrm{rCMRO}_{2}$ decrease in the subacute stage. Thirdly, there is the "no reflow phenomenon." $1,10,21,29)$

In the chronic stage, statistically significant hemodynamic disturbances appeared only in the borderzone areas. The subacute and the chronic stages showed no differences in the physiological data and the severity of stenosis. The presence of differences in hemodynamic data between subacute and chronic stages may be influenced by two factors. First, the development of collateral circulation. However, our study showed that although poor collateral circulation patients in the chronic stage had lower $\mathrm{rCBF}, \mathrm{rCMRO}_{2}$, and $\mathrm{rCBF} / \mathrm{rCBV}$ ratio than the good collateral circulation patients, the difference was not significant. Possibly, collateral circulation was not estimated objectively due to differences in timing of dye injections and the multiplicity of collateral circulation routes. Better evaluation of collateral circulation is necessary. Second, microcirculation recovery or neuronal network recovery may have occurred. These possibilities must be confirmed by further histological examinations.

Cerebral infarction is generally induced by hemodynamic disturbance or microemboli. ${ }^{5.20)} \mathrm{We}$ found that hemodynamic disturbances correlated well with main trunk stenosis. If the main trunk stenosis is the cause of the hemodynamic disturbance, surgical reconstruction may be possible. ${ }^{3,16,25)}$ In addition, $\mathrm{rCBF} / \mathrm{rCBV}$ ratio decrease, meaning perfusion pressure decrease, ${ }^{8)}$ may correlate with infarction caused by microemboli. In the chronic stage, the hemodynamic disturbances occurred mainly in borderzone areas. ${ }^{17}$ If surgical reconstruction is considered, the symptoms, especially the higher cerebral functions, may be an important indication.

\section{Acknowledgments}

The authors are grateful to Drs. S. Fukuma (Kyoto First Red Cross Hospital), S. Taketomo (Kyoto Saiseikai Hospital), S. Kubo (Kyoto Second Red Cross Hospital), K. Suzuki (Matsushita Memorial Hospital), T. Ohta (Ohshima Hospital), Y. Horikawa (Otowa Hospital), and T. Ueguchi (Rokujizo Hospital) for allowing us to study their patients, and Mr. T. Wakita, Mr. H. Horii, and Mr. R. Fujii for their skillful technical assistance.

\section{References}

1) Ames A, Wright RL, Kowada M, Thurston JM, Majno G: Cerebral ischemia. 2. The no reflow phenomenon. Amer $J$ Path 52: 437-453, 1968

2) Baron JC, Bousser MG, Rey A, Guillard A, Comar $D$, Castaigne P: Reversal of focal "misery-perfusion syndrome" by extra-intracranial arterial bypass in hemodynamic cerebral ischemia. A case study with 150 positron emission tomography. Stroke 12: 454459,1981 
3) Baron JC, Rougemont D, Soussaline F, Bustany $P$, Crouzel C, Bousser MG, Comar D: Local interrelationships of cerebral oxygen consumption and glucose utilization in normal subjects and in ischemic stroke patients: A positron tomography study. $J$ Cereb Blood Flow Metab 4: 140-149, 1984

4) Blaisdell WF, Clauss RH, Galbraith JG, Imparato AM, Wylie EJ: Joint study of extracranial arterial occlusion, JAMA 209: 1889-1895, 1969

5) Denny-Brown D: The treatment of recurrent cerebrovascular symptoms and the question of "vasospasm." Med Clin N Amer 35: 1457-1471, 1951

6) Fein JM: Extracranial to intracranial bypass grafting: Anterior circulation, in Wilkins $\mathrm{RH}$, Rengachary SS (eds): Neurosurgery. New York, McGraw-Hill, 1985, pp 1272-1280

7) Frackowiak RS, Lenzi GL, Jones T, Heather JD: Quantitative measurement of regional cerebral blood flow and oxygen metabolism in man using ${ }^{15} \mathrm{O}$ and positron emission tomography: Theory, procedure and normal values. $J$ Comput Assist Tomogr 4: 727736,1980

8) Gibbs JM, Wise RJS, Leenders KL, Jones T: Evaluation of cerebral perfusion reserve in patients with carotid artery occlusion. Lancet $1: 310-314,1984$

9) Gibbs JM, Wise RJS, Thomas DJ, Mansfield AO, Russell RWR: Cerebral haemodynamic changes after extracranial-intracranial bypass surgery. I Neurol Neurosurg Psychiatry 50: 140-150, 1987

10) Hallenbeck JM, Dutka AJ, Tanishima T, Kochanek PM, Kumaroo KK, Thompson CB, Obrenovitch TP, Contreras TJ: Polymorphonuclear leukocyte accumulation in brain regions with low blood flow during the early postischemic period. Stroke 17: 246253,1986

11) Hino A, Mizukawa $\mathrm{N}$, Tenjin $\mathrm{H}$, Imahori $\mathrm{Y}$, Taketomo S, Yano I, Nakahashi H, Hirakawa K: Postoperative hemodynamic and metabolic changes in patients with subarachnoid hemorrhage. Stroke 20: 1504-1510, 1989

12) Ingvar DH: Cerebral blood flow and metabolism in complete apallic syndromes, in states of severe dementia and in akinetic mutism. Acta Neurol Scand 49: 233-244, 1973

13) Kindt GW, Youmans JR: The effect of stricture length on critical arterial stenosis. Surg Gynec Obstet 128: 729-739, 1969

14) Kuhl DE, Phelps ME, Kowell AP, Metter EJ, Selin $C$, Winter J: Effects of stroke on local cerebral metabolism and perfusion: Mapping by emission computed tomography of $18 \mathrm{FDG}$ and $13 \mathrm{NH} 3 . \mathrm{Ann}$ Neurol 8: 47-60, 1980

15) Lammertsma AA, Jones $T$ : Correction for the presence of intravascular oxygen-15 in the steadystate technique for measuring regional oxygen extraction ratio in the brain: 1 . Description of the method. $J$ Cereb Blood Flow Metab 3: 416-424, 1983

16) Leblanc R, Tyler JL, Mohr G, Meyer E, Diksic M,
Yamamoto L, Taylor L, Gauthier S, Hakim A: Hemodynamic and metabolic effects of cerebral revascularization. J Neurosurg 66: 529-535, 1987

17) Leblanc R, Yamamoto YL, Tyler JL, Diksic M, Hakim A: Borderzone ischemia. Ann Neurol 22: 707-713, 1987

18) Meyer JS, Naritomi H, Sakai F, Ishihara N, Grant P: Regional cerebral blood flow, diaschisis, and steal after stroke. Neurol Res 1: 101-119, 1979

19) Millikan $\mathrm{CH}$ (Ad Hoc Committee on Cerebrovascular Disease): A classification and outlines of cerebrovascular disease 2. Stroke 6: 564-616, 1975

20) Millikan $\mathrm{CH}$, Siekert RG, Shick RM: Studies in cerebrovascular disease. 5. The use of anticoagulant drugs in the treatment of intermittent insufficiency of the internal carotid arterial system. Proc Mayo Clin 30: $578-586,1955$

21) Obrenovitch TP, Hallenbeck JM: Platelet accumulation in regions of low blood flow during the postischemic period. Stroke 16: 224-234, 1985

22) Ojemann RG, Crowell RM, Roberson GH, Fisher CM: Surgical treatment of extracranial carotid occlusive disease. Clin Neurosurg 22: 214-263, 1975

23) Phelps ME, Huang SC, Hoffman EJ, Kuhl DE: Validation of tomographic measurement of cerebral blood volume with C-11 labeled carboxyhemoglobin. I Nucl Med 20: 328-334, 1979

24) Powers WJ, Press GA, Grubb RL, Gado M, Raichle ME: The effect of hemodynamically significant carotid artery disease on the hemodynamic status of cerebral circulation. Ann Intern Med 106: 27-35, 1987

25) Powers WJ, Tempel LW, Grubb RL: Influence of cerebral hemodynamics on stroke risk: One-year follow-up of 30 medically treated patients. Ann Neurol 25: 325-330, 1989

26) Strong AJ, Tomlinson BE, Venables GS, Gibson G, Hardy JA: The cortical ischaemic penumbra associated with occlusion of the middle cerebral artery in the cat: 2 . Studies of histopathology, water content, and in vitro neurotransmitter uptake. J Cereb Blood Flow Metab 3: 97-108, 1983

27) Tenjin $\mathrm{H}$, Ueda S, Mizukawa $\mathrm{N}$, Imahori $\mathrm{Y}$, Hino $\mathrm{A}$, Ohmori Y, Furuya S, Oki F, Yamashita M, Nakahashi $\mathrm{H}$ : The changes in hemodynamics with agings. Kyoto Furitsu Ika Daigaku Zasshi 98: 10871093, 1989 (in Japanese)

28) Torvik A: The pathogenesis of watershed infarcts in the brain. Stroke 15: 221-223, 1984

29) Turcani $P$, Gotoh F, Ishihara N, Tanaka K, Gomi S, Takashima S, Mihara B: Are blood platelets involved in the pathogenesis of ischemic brain edema in gerbils? Stroke 19: 486-489, 1988

30) Uemura K: Regional cerebral blood flow and oxygen metabolism in ischemic stroke and hypertensive intracerebral hemorrhage. Neurosurgeons 6: 57-70, 1987 (in Japanese)

31) Van Der Eechen HM, Adams RD: Anatomy and functional significance of meningial anastomoses of 
human brain. J Neuropath Exp Neurol 12: 132-157, 1953

32) Wing SD, Norman D, Pollock JA, Newton TH: Contrast enhancement of cerebral infarcts in computed tomography. Radiology 121: 89-92, 1976

33) Yamauchi H, Fukuyama H, Kimura J, Konishi J, Kameyama $\mathrm{M}$ : Hemodynamics in internal carotid artery occlusion examined by positron emission tomography. Stroke 21: 1400-1406, 1990

34) Yonekawa $Y$ : Nogekateki chiryo no tekiou, in Kikuchi H (ed): Heisokusei Keidomyaku Shikkan. Tokyo, Igaku Shoin, 1986, pp 164-172 (in Japanese)
35) Yonekawa Y, Yasargil MG: Extra-intracranial arterial anastomosis: Clinical and technical aspects. Results, in Krayenbuhl H (ed): Advances and Technical Standards in Neurosurgery, vol 3. Wien, Springer, 1976, pp 47-78

Address reprint requests to: H. Tenjin, M.D., Department of Neurosurgery, Kyoto Prefectural University of Medicine, 465 Kajii-cho, Hirokoji-agaru, Kawaramachi-dori, Kamigyo-ku, Kyoto 602, Japan. 